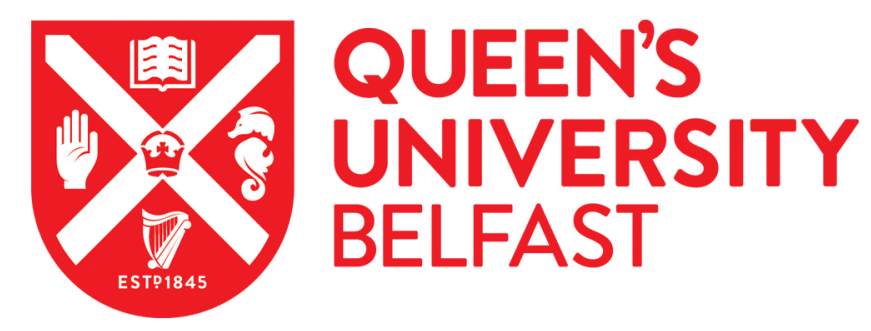

\title{
Earthquake aftershock anxiety: An examination of psychosocial contributing factors and symptomatic outcomes.
}

Dorahy, M. J., Renouf, C., Rowlands, A., Hanna, D., Britt, E., \& Carter, J. D. (2016). Earthquake aftershock anxiety: An examination of psychosocial contributing factors and symptomatic outcomes. Journal of Loss and Trauma, 21(3), 246-258. https://doi.org/10.1080/15325024.2015.1075804

Published in:

Journal of Loss and Trauma

Document Version:

Peer reviewed version

Queen's University Belfast - Research Portal:

Link to publication record in Queen's University Belfast Research Portal

Publisher rights

(c) 2016 Taylor \& Francis

This is an Accepted Manuscript of an article published by Taylor \& Francis in Journal of Loss and Trauma on 18 Aug 2015, available online: http://www.tandfonline.com/doi/full/10.1080/15325024.2015.1075804

\section{General rights}

Copyright for the publications made accessible via the Queen's University Belfast Research Portal is retained by the author(s) and / or other copyright owners and it is a condition of accessing these publications that users recognise and abide by the legal requirements associated with these rights.

Take down policy

The Research Portal is Queen's institutional repository that provides access to Queen's research output. Every effort has been made to ensure that content in the Research Portal does not infringe any person's rights, or applicable UK laws. If you discover content in the Research Portal that you believe breaches copyright or violates any law, please contact openaccess@qub.ac.uk. 
Earthquake aftershock anxiety: An examination of psychosocial contributing factors and symptomatic outcomes

Martin J. Dorahy, Charlotte Renouf, Amy Rowlands

Department of Psychology, University of Canterbury, New Zealand

Donncha Hanna

School of Psychology, The Queen’s University of Belfast, Northern Ireland

Eileen Britt, Janet D. Carter

Department of Psychology, University of Canterbury, New Zealand

Running head: EFFECTS OF AFTERSHOCKS ON PSYCHOLOGICAL SYMPTOMS

Author Note

Martin J. Dorahy, Department of Psychology, University of Canterbury, Christchurch, New Zealand, The Cannan Institute, Belmont Private Hospital, Brisbane, Australia; Charlotte Renouf, Amy Rowlands, Eileen Britt, Janet D. Carter, Department of Psychology, University of Canterbury, Christchurch, New Zealand; Donncha Hanna, School of Psychology, the Queen's University of Belfast, Northern Ireland.

Correspondence concerning this article should be addressed to Martin J. Dorahy, Department of Psychology, University of Canterbury, Private Bag 4800, Christchurch, 8140, New Zealand. Email: martin.dorahy@canterbury.ac.nz 


\begin{abstract}
This study examined the direct and indirect effects of cognitions and anxiety associated with aftershocks on psychological symptoms (anxiety, depression, acute stress) and daily functioning (general and relationship). Participants were 600 adults from Christchurch. Data collection was approximately four months after the fatal 2011 earthquake. Path analysis was used. Socioeconomic status was directly associated with appraisals of uncontrollability of response to aftershocks. These cognitions were directly related to aftershock anxiety, which heightened general anxiety, depression and acute stress symptoms. These symptoms were directly associated with relationship and general life dysfunction. Aftershock anxiety plays a significant role in ongoing psychological distress associated with earthquakes.
\end{abstract}

Keywords: earthquake, aftershocks, anxiety, depression, acute stress 
Earthquake aftershock anxiety: An examination of psychosocial contributing factors and symptomatic outcomes

Unlike many other natural disasters, earthquakes occur without warning, and often linger for days, months and sometimes years in the form of ongoing aftershocks (National Center for PTSD, 2012). Aftershocks can act as a powerful visceral stimulus for the reactivation of terror, uncertainty, helplessness, and confusion (Başoğlu \& Salcioğlu, 2011; Kashima, 2011). Thus, along with physical and psychological problems they may directly create, aftershocks may retrigger and strengthen quake-related schema associated with stress, fear and depression (c.f., Adessky \& Freeman, 2005).

Studies of earthquake survivors mention exposure to ongoing aftershocks (e.g., Sattler et al., 2006; Wang et al., 2000), but few examine the direct and indirect impact of aftershock anxiety. Bödvarsdóttir and Elklit (2004) found that 92\% of their earthquake sample reported fear of small tremors. Kuwabara et al. (2008) found that when retrospectively assessed five months after the 2004 Niigata-Chuetsu earthquake, increased fear of aftershocks predicted immediate distress. These studies suggest anxiety related to aftershocks may increase general psychological symptoms like anxiety, depression and posttraumatic stress. Such symptoms may impact on a person's ability to function in daily life (APA, 2000). Thus aftershock anxiety may heighten symptoms that in turn reduce psychosocial functioning. But what mechanisms might underpin aftershock anxiety? Kannis-Dymand et al. (2015) found that cognitions around concern and worry (e.g., “is the big one coming again”) were common during aftershocks. Dorahy and 
Kannis-Dymand (2012) found that specific cognitions around the perceived inability to control responses to aftershocks predicted acute stress, depression and anxiety symptoms, but anxiety seemed to be the key variable connecting lack of perceived response control during aftershocks to acute stress and depression. These studies suggest that cognitions around response incontrollability to aftershocks may increase aftershock anxiety, which in turn increases symptoms and reduces functioning.

Work following the 2010 and 2011 Christchurch, New Zealand, earthquakes found community-level (e.g., neighborhood damage; socioeconomic status of suburb) and individual-level (e.g., disruption and loss caused by earthquakes) variables were important in the prediction of post-earthquake psychological symptoms and psychosocial functioning (Dorahy \& Kannis-Dymand, 2012; Dorahy et al., 2015). For example, suburbs with different levels of earthquake damage and different levels of financial resources had different degrees of earthquake-related disruption and loss, and these variables had varying influences on post-earthquake symptoms and functioning. Consequently neighborhood damage, socioeconomic status, and earthquake-related disruption and loss may be hypothesized to play a role in aftershock response controllability and anxiety.

The current study examined the direct and indirect impact of aftershocks four months after the February 2011 Christchurch earthquake that killed 185 people. The region had been struck by over 13,000 aftershocks occurring effectively on a daily basis since a 7.1 magnitude quake (4.35am) on September $4^{\text {th }} 2010$ (depth: $11 \mathrm{~km}$, location: $37 \mathrm{~km}$ from the city). There were no deaths following this quake, despite major structural damage and property destruction. The fatal 6.3 magnitude quake on February $22^{\text {nd }} 2011$ 
occurred shortly after midday (12.51pm), and was shallower (6km) and closer to the city centre $(6.7 \mathrm{~km})$. Between the September and February earthquakes, the region experienced over 4000 aftershocks, and between the February quake and the beginning of June 2011, 3600 aftershocks were registered, 99 of these above magnitude 4 (7 above magnitude 5). Aftershocks persisted on a continuing basis throughout data collection, and while causing no more deaths, further promulgated property and infrastructure damage.

This study explored how level of exposure to earthquake-related neighborhood damage, socioeconomic status, earthquake-related disruption, and personal/material losses in the presence of ongoing aftershocks impact on appraisals and anxiety associated with aftershocks following the February 2011 Christchurch earthquake. In addition, the influence of these aftershock variables (i.e., appraisals and anxiety) on acute stress, depression and anxiety symptoms, along with general and relationship functioning was examined. Being guided by the empirical findings outlined above a model was specified (See Figure 1) and path analysis was used to assess direct and indirect effects.

\section{Method}

\section{Participants}

Participants were 600 residents living in six suburbs $(n=100)$ of Christchurch, New Zealand. Suburbs were chosen based on two variables: the physical impact of the earthquake ('neighborhood damage') and socioeconomic status ('SES'). The first three suburbs were chosen because they came from three different socioeconomic levels (low, medium and high), and were severely affected by the earthquake having large-scale property loss and loss of utilities (water, sewage electricity) for weeks and sometimes months. For each of these affected suburbs a matched suburb based on demographic 
variables (e.g., number of people in suburb, their average age and gender) and socioeconomic level was found that was relatively unaffected by the earthquake. These three suburbs experienced less overall damage to homes and properties and had minimal loss of utilities (see Dorahy et al., 2015).

The six community groups did not differ in age, with the exception of the low SES, relatively unaffected group (43.49), which did not differ from its matched suburb (i.e., low SES, affected group; 47.93) but was significantly younger than those from the high SES affected and relatively unaffected groups and the medium SES relatively unaffected group, $\mathrm{F}(5,592)=5.69, \mathrm{p}<.05$. Overall, the sample ranged from 18-90 years $(\mathrm{M}=49.69 ; S D=15.80)$. The suburbs did not differ in terms of sex, $\chi^{2}(5, \mathrm{~N}=600)=.54$ $p=$ ns, with the overall sample consisting of 218 males and 382 females.

\section{Materials}

The survey battery was administered in the following order: The 19-item Acute Stress Disorder Scale (ASDS) (Bryant, Moulds, \& Guthrie, 2000) assessed on a Likert scale from 1 (not at all) to 5 (very much); the Patient Health Questionnaire 9-item depression module (PHQ-9) (Spitzer, Kroenke, \& Williams, 1999) assessed on a Likert scale from 0 (not at all) to 3 (nearly every day); and the Generalized Anxiety Disorder-7 item scale (GAD-7) (Spitzer, Kroenke, Williams, \& Löwe, 2006) assessed on a Likert scale from 0 (not at all) to 3 (nearly every day). All items were anchored to experiences since the February 22nd, 2011 earthquake, and specifically referred to the ongoing aftershocks (or earthquake where relevant). The ASDS was used in place of a PTSD scale because aftershocks were ongoing and anecdotal reports suggested that some people where finding the aftershocks more distressing then the February earthquake. The ASDS 
contains the symptoms of DSM-IV PTSD, plus dissociative symptoms, thus was a good marker of trauma symptoms. Following administration of these questionnaires participants' age and sex were assessed and they were asked dichotomous response ('yes/no') questions regarding whether they lived without electricity, water, and sewage for two or more days following the quake, and whether they had to move house as a result of the quake ('disruption'). They also responded on a weighted scale to whether they had lost anything (e.g., house, family member, pets, job) from the quake ('loss’). Cognitive markers related to the aftershocks were assessed using two questions which measured the extent participants believed they could a) predict, and b) control, their responses to the aftershocks (e.g., How much do you believe you can control your response to these aftershocks?). These were rated on a 10-point Likert scale. The two items were averaged, and referred to as 'control over aftershocks'. Higher scores indicated less controllability of responses to aftershocks. Anxiety associated with the ongoing occurrence of aftershocks (i.e., the emotional marker) was measured by 2 items assessing a) anxiety and b) a felt sense of being 'on edge' as a result of the aftershocks (e.g., 'How anxious do these aftershocks make you?'). These items were measured on a 10-point scale and averaged, with higher scores indicating increased aftershock anxiety. This variable was referred to as 'aftershock anxiety.' Finally, questions addressing daily and relationship functioning were administered. These were assessed on a 0 (N/A) to 5 (extreme) point Likert scale with participants asked about the degree to which the earthquakes had disrupted their work, household tasks, leisure activities, family unit, and relationship with partner, children, and family/friends. Responses to functioning in the first four areas were averaged to obtain a score for disruptions in general life functioning 
('general functioning'), while the latter three were averaged to get a score for disruptions to relationship functioning ('relationship functioning'). Breaking the items in this way was confirmed by factor analysis (See Dorahy et al., 2015).

\section{Procedure}

A door-to-door survey methodology was utilized in each suburb. Data collection commenced four months after the February $22^{\text {nd }}$ earthquake and had a two-month window. Notably, shortly after the start of data collection two large aftershocks were experienced on the same day (June $13^{\text {th }}, 2011,1.00 \mathrm{pm}$, Magnitude 5.89; 2.20pm, Magnitude 6.41; http://www.canterburyquakelive.co.nz/). The study was approved by the University of Canterbury Human Ethics Committee.

\section{Statistical Analysis}

To test the models, path analysis with full information maximum likelihood estimation was specified in Amos 18.0. Model fit was assessed by a range of fit indices as proposed by Hoyle and Panter (1995). These were the chi-square test, the root mean square error of approximation (RMSEA), the comparative fit index (CFI), and the Tucker-Lewis index (TLI). A non-significant chi-square test, a RMSEA of less than 0.06, and CFI and TLI values greater than 0.95 were considered evidence of desirable model fit (Hu \& Bentler, 1999).

There was missing data for 22 participants (3.6\%) so these cases were removed. Mahalanobis d-squared values were checked for individual cases to screen for influential multivariate outliers for each model. This led to the removal of $40(6.7 \%)$ cases in the anxiety model, 30 (5\%) cases in the (acute) stress model, and 37 (6.2\%) cases in the depression model (Aivazian, Filzmoser \& Kharin, 2004). Thus, the final sample size used 
for analyses ranged from 538 to 548. The data was then screened for non-normality. The variables were assumed to approximate univariate normality, as values of all variables for skewness and kurtosis were less than 1.6 and 2 respectively (Kline, 1986). Additionally the overall data did approximate multivariate normality; Mardia’s coefficient for the anxiety, stress and depression models were .45, -1.2, and -.66 respectively (Hu \& Bentler, 1999).

\section{Results}

The initial model was specified and estimated based on model 1 (see Figure 1 while separate models were run for stress, anxiety and depression, for ease of explication they are depicted together).

***Insert Figure 1 about here $* * *$

The initial models for anxiety, stress and depression each demonstrated path coefficients with weak, non-significant standardized regression weights; therefore separate models were specified and estimated, with different combinations of the weak, non-significant paths trimmed (Duncan, 1975). The most parsimonious model in each case had all of the weak non-significant paths trimmed. These models demonstrated excellent model fit on all four indices (Anxiety: $\chi^{2}=33.23 d f=18, p=.016$, RMSEA $(90 \% \mathrm{CI})=.04(.02-.06), \mathrm{CFI}=.99, \mathrm{TLI}=.98 ;$ Stress: $\chi^{2}=30.21 d f=19, p=.049$, RMSEA $(90 \% C I)=.03(0-.05)$, CFI = .99, TLI = .99; Depression: $\chi^{2}=33.68 d f=18 ; p$ $=.014, \mathrm{RMSEA}(90 \% \mathrm{CI})=.04(.02-.06), \mathrm{CFI}=.99, \mathrm{TLI}=.98)$.

Table 1 contains the significant standardized regression coefficients (direct effects) and total effects for each separate trimmed model, to show similarities and differences in path coefficients. 
***Insert Table 1 about here ${ }^{* * *}$

Due to the focus of the paper, attention is specifically given to aftershock variables and their endogenous and exogenous influences. Overall, the aftershock variables (i.e., cognitive: control of aftershocks, and emotional: aftershock anxiety) had a similar effect on anxiety, depression and acute stress. In terms of endogenous influences of the cognitive and emotional markers of aftershocks (see Table 1), SES level had a direct effect on cognitive appraisal, with participants from lower socioeconomic neighborhoods reporting less controllability of responses to aftershocks. SES level also had a small indirect effect on aftershock anxiety through physical disruption caused by the quake (i.e., losing utilities/moving house). Neighborhood damage (i.e., living in damaged or relatively undamaged neighborhoods) had no direct or indirect effects on the aftershock variables. In term of exogenous influences, uncontrollability of responses to aftershocks had a direct effect on heightened aftershock anxiety and an indirect effect on psychological symptoms (i.e., anxiety, depression, acute stress) through aftershock anxiety. Aftershock anxiety had a direct effect on psychological symptoms, with those being more anxious about aftershocks experiencing more general anxiety, depression and acute stress symptoms. Neither the cognitive nor emotional marker of aftershocks were directly associated with impairment in functioning (i.e., general and relationship). Yet both aftershock markers had indirect effects on functioning disruptions through psychological symptoms, with the exception that the cognitive marker had no indirect effect on relationship disruption in the anxiety model. The indirect effect for aftershock anxiety on disruption in functioning was stronger than for uncontrollability of aftershock response. Figure 2 draws together the findings associated with the two aftershock 
markers (i.e., all variables except neighborhood damage, which was not related to the aftershock markers) by outlining the model and with arrow thickness representing comparative regression weights when anxiety, depression, and acute stress are depicted together.

***Insert Figure 2 about here $* * *$

\section{Discussion}

The psychological impact of aftershocks has been relatively neglected in the earthquake literature. This study used a large, well-matched community sample to extend the earlier work of Dorahy and Kannis-Dymand (2012), and examined emotional (anxiety) and cognitive (controllability of response) components of the psychological experience of aftershocks. It showed that ongoing aftershocks have a significant role to play in psychological difficulties following the onset of an earthquake series. The model of best fit indicated a coherent pattern of direct effects from which neighborhood SES level, but not degree of physical damage, was associated with heightened beliefs that responses to aftershocks were more uncontrollable. This cognitive appraisal was directly and strongly associated with increases in how anxious participants felt about aftershocks. The emotional component of aftershocks in turn was associated with heightened anxiety, depression and acute stress symptoms, and these symptoms directly influenced problems in general and relationship functioning. SES had an indirect effect on aftershock anxiety through physical disruptions. The influence of controllability of response to aftershocks on anxiety, depression and acute stress symptoms was mediated through aftershock anxiety. Controllability of response to aftershocks also had a weak indirect effect on 
general and relationship functioning through aftershock anxiety and psychological symptoms. The influence of aftershock anxiety on relationship and general functioning was mediated through anxiety, depression and acute stress symptoms. In short and importantly, aftershock anxiety and controllability of response were stronger predictors of psychological symptoms than other variables, including the extent of neighborhood damage, loss, and disruptions.

The cognitive component of aftershock anxiety was assessed by examining the degree to which participants believed they could predict and control their response when an aftershock was experienced. That is, the degree to which they thought they could govern and contain their emotional, cognitive and behavioral responses to aftershocks. Previous work has identified the impact that overwhelming experiences can have on basic assumptions about the self and the world. For example, victims highly exposed to a fatal bus crash continued to have less belief in the benevolence of the world seven years after the crash compared to those more indirectly exposed (Solomon, Iancu, \& Tyano, 1997). Those with less belief in a benevolent world had more psychological distress, including PTSD, depression and anxiety. Alterations in predictability/controllability are central features of the basic assumptions underpinning posttraumatic adaptation (Janoff-Bulman, 1992). Solomon et al. (1997) note there are two underpinning basic assumptions: a) that individuals strive to create a stable balance between their beliefs and external events and, b) they work to maintain their current convictions. Arguably, both these are influenced considerably by lack of controllability/predictability of psychological and behavioral responses to the environment, and they have in various ways been related to postearthquake distress (Dorahy \& Kannis-Dymand, 2012; Greening, Stoppelbein, \& Doctor, 
2002). The current findings suggest that appraisals about responses to aftershocks lead to aftershock anxiety and then onto general psychological symptoms. That is, assuming oneself is less able to effectively manage psychological and behavioral responses to aftershocks is likely to heighten aftershock anxiety, which appears to initiate and/or maintain post-earthquake psychological problems. Maintenance of post-earthquake problems might be brought about by aftershocks re-activating cognitions and emotions associated with the initial quake (Kashima, 2011), while also eroding a sense of selfefficacy in attempting to move beyond these difficulties. With such assumptions about one's response to aftershocks, the world becomes less benevolent and safe, and aftershocks create more anticipatory anxiety and threat. In order to further address these findings and interpretations, longitudinal work should examine the degree to which aftershock anxiety causes, or is caused by, heightened psychological symptoms.

While neighborhood damage was not associated with aftershock variables, living in a lower SES area was associated with higher beliefs that responses to aftershocks were uncontrollable. SES level is associated with the degree to which resources are available in the aftermath of a disaster (Hobfoll, 2001). Those from lower SES areas are likely to have less access to resources (Dorahy et al., 2015). Thus, when a disaster occurs, those from low SES areas are likely to lose the resources they once had, and may have fewer resources in reserve to draw upon. Loss of resources following natural disasters such as earthquakes has been consistently associated with psychological distress (Freedy, Saladin, Kilpatrick, Resnick, \& Saunders, 1994; Hobfoll, 2001; 2011). Resources have been grouped into the following: object (e.g., house), condition (e.g., relationship status), personal (e.g., key skills, personal characteristics), and energy (e.g., money) (Hobfoll, 
2011). The current findings suggest that living in low SES areas is associated with appraisals about being unable to control and predict aftershock responses, which falls under personal resources. Thus in the aftermath of an earthquake and in the presence of ongoing aftershocks, SES level may influence the degree to which individuals believe they are psychologically able to manage their feelings and behavioral responses to aftershocks, perhaps thinking that if their physical world is not controllable/predictable (due in part to loss of object, energy and condition resources) then neither is their psychological world in the face of ongoing stressors.

Research suggests that the capacity to psychologically function effectively in life (e.g., work, parental roles) and in relationships may be severely affected by a natural disaster such as an earthquake (Bonanno et al., 2010; Norris et al., 2002). Impact on functioning has been proposed to come directly from post-earthquake psychological distress (e.g., posttraumatic, anxiety, depression symptoms), ongoing distress created by aftershocks, or factors associated with socioeconomic (e.g., money, housing) and psychosocial (e.g., support) resources (Dorahy \& Kannis-Dymand, 2012; Sattler et al., 2006). With regard to aftershocks, the current study indicated that the cognitive and emotional markers of aftershock distress have an indirect impact on post-quake functioning through the mediator of psychological symptoms. Thus, general and relational functioning outcomes are a direct consequence of psychological symptoms, associated aftershock cognitions, and anticipatory feelings.

A limitation of the current study was that while psychological distress (anxiety, depression and acute stress symptoms) was anchored to symptoms commencing after the February $22^{\text {nd }}$ earthquake, these symptoms were not solely isolated to the aftershocks per 
se. What was clear however, is that aftershock cognitions (indirectly) and anxiety (directly) were associated with severity of post-quake symptoms. Another limitation was that variables were assessed by self-report months after the quakes started. Bonanno et al. (2010) note that self-report of mental health difficulties is prone to inaccurate reporting due to recall biases associated with current mental state. This was attempted to be minimized by having a relatively brief lag time between the disaster and data collection (approximately four months), although inaccuracies still may have been evident. For example, people may have averaged symptoms to produce a lower score, amplified distress in cases where symptoms had been memorable, or engaged in the recency principle and limited assessment to recent times (e.g., past week). Finally, due to the absence of more sophisticated tools to assess some variables, including the aftershock variables, short, non-validated measurements were utilized.

Aftershocks make a significant contribution to mental health outcomes following the onset of seismic activity. In the current study, the belief that responses to ongoing tremors were uncontrollable heightened anticipatory anxiety associated with aftershocks, which directly influenced anxiety, depression and acute stress symptoms more than other predictors included in the model. Psychological symptoms mediated the association between aftershock anxiety and functional disruptions in relationship and general life. Future research would benefit from examining whether aftershocks independently contribute to mental health difficulties following an earthquake, or whether they have a maintaining function, for example by constantly triggering quake-related schema associated with the onset event, which is typically the most deadly and distressing. 


\section{References}

Adessky, R.S., \& Freeman, S.A. (2005). Treating survivors of terrorism while adversity continues. Journal of Aggression, Maltreatment and Trauma, 10, 443-454. doi:10.1300/J146v10n01_03

American Psychiatric Association (2000). Diagnostic and statistical manual of mental disorders (4th ed.) Text revision. Washington, DC: Author.

Aivazian, S., Filzmoser, P., \& Kharin, Y. (2004). Computer Data Analysis and Modelling: Robustness and Computer Intensive Methods. Proceedings of the Seventh International Conference. Minsk: Belarusian State University.

Bașoğlu, M., \& Salcioğlu, E. (2011). A mental healthcare model for mass trauma survivors: Control-focused behavioral treatment of earthquake, war and torture trauma. Cambridge: Cambridge University Press.

Bödvarsdóttir, I., \& Elklit, A. (2004). Psychological reactions in Icelandic earthquake survivors. Scandinavian Journal of Psychology, 45, 3-13. doi: 10.1111/j.14679450.2004.00373.x

Bonanno, G. A., Brewin, C. R., Kaniasty, K., \& La Greca, A. M. (2010). Weighing the cost of disasters: Consequences, risks, and resilience in individuals, families, and communities. Psychological Science in the Public Interest, 11, 1-49. doi: $10.1177 / 1529100610387086$

Bryant, R. A., Moulds, M. L., \& Guthrie, R. M. (2000). Acute stress disorder scale: A self-report measure of acute stress disorder. Psychological Assessment, 12, 61-68. doi: 10.1037/1040-3590.12.1.61 
Dorahy, M. J., \& Kannis-Dymand, L. (2012). Psychological distress following the 2010 Christchurch earthquake: A community assessment of two differentially affected suburbs. Journal of Loss and Trauma, 17, 203-217. doi:

10.1080/15325024.2011.616737

Dorahy, M. J., Rowlands, A., Renouf, C., Hanna, D., Britt, E., \& Carter, J. D. (2015). Impact of average household income and damage exposure on post-earthquake distress and functioning: A community study following the February 2011 Christchurch earthquake. British Journal of Psychology.

Duncan, O.D. (1975). Introduction to Structural Equation Models. New York: Academic Press.

Freedy, J. R., Saladin, M. E., Kilpatrick, D. G., Resnick, H. S., \& Saunders, B. E. (1994). Understanding acute psychological distress following natural disaster. Journal of Traumatic Stress, 7(2), 257-273. doi: 10.1002/jts.2490070207

Greening, L., Stoppelbein, L., \& Doctor, R. (2002). The mediating effects of attributional style and event-specific attributions on postdisaster adjustment. Cognitive Therapy \& Research, 26, 261-274. doi: 10.1023/A:1014530021675

Hobfoll, S. E. (2001). The influence of culture, community, and the nested-self in the stress process: Advancing Conversation of Resource theory. Applied Psychology: International Review, 50, 337-369. doi: 10.1111/1464-0597.00062

Hobfoll, S. E. (2011). Conservation of resources theory: Its implications for stress, health and resilience. In S Folkman (Ed.), The Oxford handbook of stress, health and coping. (pp. 127-147). Oxford: Oxford University Press.

Hoyle, R. H., \& Panter, A. T. (1995). Writing about structural equation models. In R. H. 
Hoyle (Ed.), Structural equation modeling: Concepts, issues, and applications (pp. 158-176). Thousand Oaks, CA: Sage.

Hu, L., \& Bentler, P.M. (1999). Cutoff criteria for fit indexes in covariance structure analysis: Conventional criteria versus new alternatives. Structural Equation Modeling, 6(1), 1-55. doi: 10.1080/10705519909540118

Janoff-Bulman, J. (1992). Shattered assumptions: Towards a new psychology of trauma. New York: The Free Press.

Kannis-Dymand, L., Dorahy, M. J., Crake, R., Gibbon, P., \& Luckey, R. (2015). An exploration of reported cognitions during an earthquake and its aftershocks: Differences across affected communities and associations with psychological distress. Journal of Nervous and Mental Disease, 203, 279-286.

Kashima, H. (2011). Mental health care and East Japan great earthquake (Editorial). Psychiatry and Clinical Neurosciences, 53, 207-212.

Kline, P. (1986). A handbook of test construction: Introduction to psychometric design. London: Methuen \& Co.

Kuwabara, H., Shioiri, T., Toyabe, S-I., Kawamura, T., Koizumi, M., Ito-Sawamura, M., Akazawa, K., \& Someya, T. (2008). Factors impacting on psychological distress and recovery after the 2004 Niigata-Chuetsu earthquake, Japan: Communitybased study. Psychiatry and Clinical Neurosciences, 62, 503-507. doi: 10.1111/j.1440-1819.2008.01842.

National Center for PTSD (January 12 ${ }^{\text {th }}$, 2012). Traumatic effects of specific types of disasters: Earthquakes. Retrieved from 
http://www.PTSD.va.gov/PTSD/professional/pages/traumatic-effects-

disasters.asp

Norris, F. H., Friedman, M. J., Watson, P. J., Byrne, C. M., Diaz, E., \& Kaniasty, K. (2002). 60,000 disaster victims speak: Part I. An empirical review of the empirical literature, 1981-2001. Psychiatry, 65, 207-239. doi: 10.1521/psyc.65.3.207.20173

Sattler, D.N., De Alvarado, A.M.G., de Castro, N.B., Van Male, R., Zetino, A.M., \& Vega, R. (2006). El Salvador earthquakes: Relationships among Acute Stress Disorder symptoms, depression, traumatic event exposure, and resource loss. Journal of Traumatic Stress, 19 (6), 879-893. doi: 10.1002/jts.20174

Solomon, Z., Iancu, I., \& Tyano, S. (1997). World assumptions following disaster. Journal of Applied Social Psychology, 27, 1785-1798. doi: 10.1111/j.15591816.1997.tb01625.x

Spitzer, R.L., Kroenke, K., \& Williams, J.B.W. (1999). Validation and utility of a selfreport version of PRIME-MD: The PHQ Primary Care Study. Journal of the American Medical Assoiation, 282(18), 1737-1744. doi:

10.1001/jama.282.18.1737

Spitzer, R.L., Kroenke, K., Williams, J.B.W., \& Lowe, B. (2006). A brief measure for assessing generalized anxiety disorder. Archives of Internal Medicine, 166, 10921097. doi: 10.1001/archinte.166.10.1092

Wang, X., Gao, L., Shinfuku, N., Zhang, H., Zhao, C., \& Shen, Y. (2000). Longitudinal study of earthquake related PTSD in a randomly selected community sample in North China. American Journal of Psychiatry, 157, 1260-1266. doi: 10.1176/appi.ajp.157.8.1260 


\section{Brief Bios}

Martin Dorahy, $\mathrm{PhD}$, is associate professor in the Department of Psychology, University of Canterbury. He has a research and clinical interest in the impact of traumatic stress on cognitive, affective and relational functioning.

Charlotte Renouf, PGDipClinPsych, is a clinical psychologist working with the Canterbury District Health Board treating patients with severe anxiety disorders, including those struggling with post-traumatic stress and adjustments disorders related to the Canterbury earthquake sequence.

Amy Rowlands, MSc Psych, is working for a mental health organisation supporting people with their recovery, and those dealing with the aftermath of Canterbury earthquakes.

Donncha Hanna, PhD, is a lecturer and research coordinator in the School of Psychology, Queens University of Belfast. His research interests include the measurement and modelling of psychological trauma, anxiety disorders and related constructs.

Eileen Britt, PhD, is Senior Lecturer in the Department of Psychology, University of Canterbury. She has research interests in a variety of clinical areas including traumatic stress, and research and clinical interests in motivational interviewing.

Janet Carter, $\mathrm{PhD}$, is an Associate Professor in the Department of Psychology at the University of Canterbury. Her research and clinical focus is on adult mental health problems particularly anxiety, depression and eating disorders. 
Figure 1: Schematic of initial proposed model

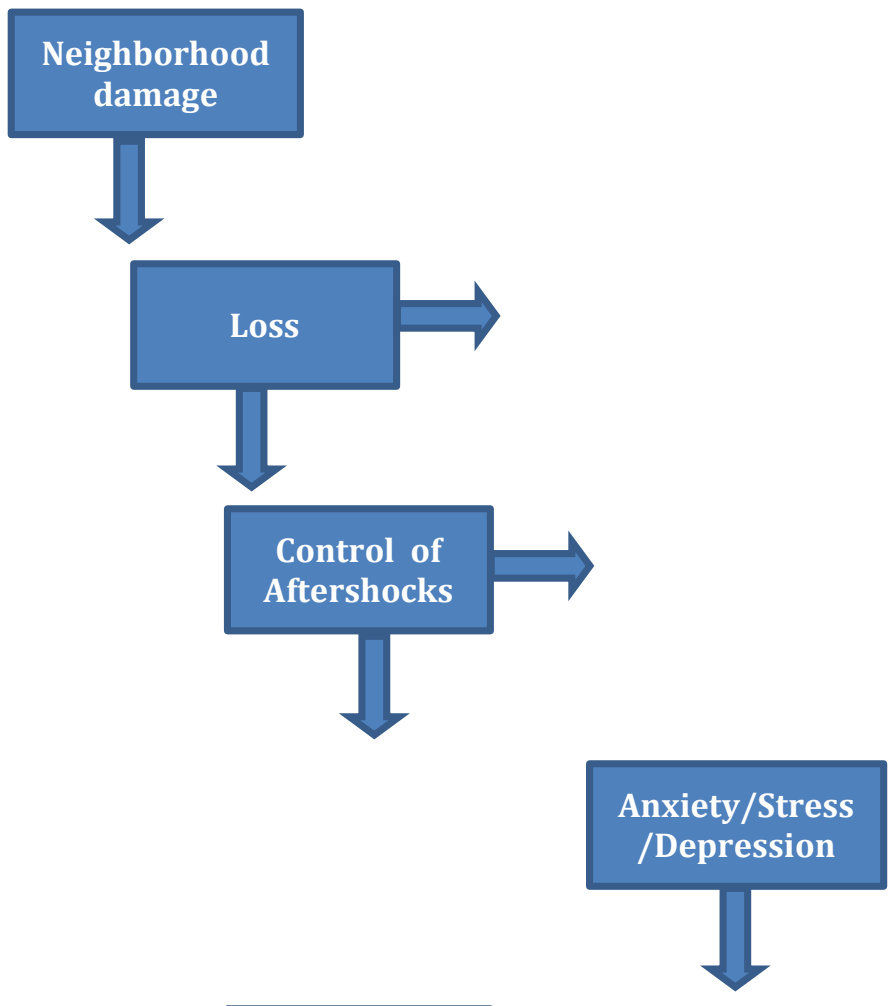

General

Functioning

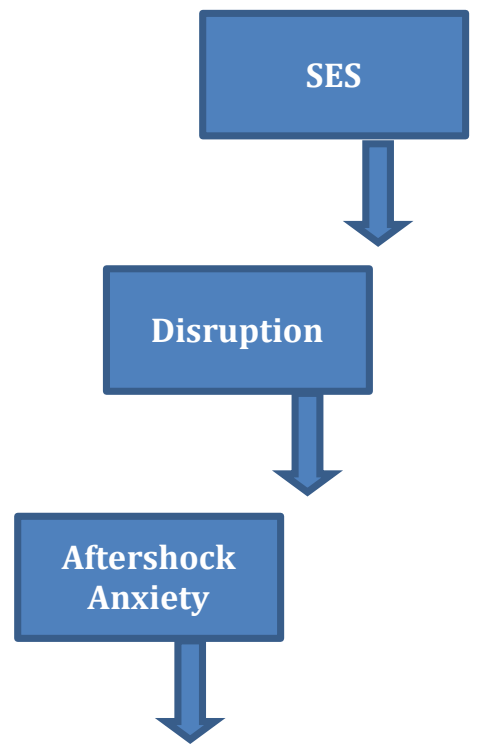

Anxiety/Stress

/Depression

Note: Due to the large number of paths proposed the above diagram indicates the causal order the model represented. Each variable was proposed to influence every variable beneath it. For example, a direct path was specified from neighborhood damage to loss, disruption, control over aftershocks, aftershock anxiety, general anxiety/stress/depression, general functioning and relationship functioning. In contrast, the variables (of either) anxiety/stress/depression were only specified to directly influence general function and relationship functioning. In addition there are two horizontal paths specified; loss directly influencing disruption, and control over aftershocks directly influencing edginess due to aftershocks (Dorahy \& Kannis-Dymand, 2012). 
Table 1: Standardized regression coefficients (direct effects) with Standardized total effects (direct and indirect effects) in parentheses

$\begin{array}{ccc}\text { Anxie- } & \text { Acute } & \text { Depre- } \\ \text { ty } & \text { Stress } & \text { ssion } \\ \text { (GAD) } & \text { (ASDS- } & \text { (PHQ) }\end{array}$

tot.)

\begin{tabular}{|c|c|c|c|}
\hline Neighborhood damage $\rightarrow$ Loss & $\begin{array}{c}- \\
\text { (na) }\end{array}$ & $\begin{array}{c}- \\
\text { (na) }\end{array}$ & $\begin{array}{c}- \\
\text { (na) }\end{array}$ \\
\hline Neighborhood damage $\rightarrow$ Disruption & $\begin{array}{c}.60 \\
(.60)\end{array}$ & $\begin{array}{c}.60 \\
(.60)\end{array}$ & $\begin{array}{c}.60 \\
(.60)\end{array}$ \\
\hline Neighborhood damage $\rightarrow$ Control over aftershocks & $\begin{array}{l}- \\
(-)\end{array}$ & $\begin{array}{c}- \\
(-)\end{array}$ & $\begin{array}{l}- \\
(-)\end{array}$ \\
\hline Neighborhood damage $\rightarrow$ Aftershock anxiety & $\begin{array}{l}- \\
(-)\end{array}$ & $\begin{array}{l}- \\
(-)\end{array}$ & $\begin{array}{l}- \\
(-)\end{array}$ \\
\hline Neighborhood damage $\rightarrow$ Anxiety/stress/depression & $\begin{array}{c}.18 \\
(.23)\end{array}$ & $\begin{array}{c}- \\
(.17)\end{array}$ & $\begin{array}{c}.17 \\
(.17)\end{array}$ \\
\hline Neighborhood damage $\rightarrow$ General Functioning & $\begin{array}{c}.22 \\
(.41)\end{array}$ & $\begin{array}{c}.21 \\
(.40)\end{array}$ & $\begin{array}{c}.21 \\
(.40)\end{array}$ \\
\hline Neighborhood damage $\rightarrow$ Relationship Functioning & $\begin{array}{c}- \\
(.17) \\
\end{array}$ & $\begin{array}{c}- \\
(.15) \\
\end{array}$ & $\begin{array}{c}- \\
(.15) \\
\end{array}$ \\
\hline $\mathrm{SES} \rightarrow$ Loss & $\begin{array}{c}- \\
\text { (na) }\end{array}$ & $\begin{array}{c}- \\
\text { (na) }\end{array}$ & $\begin{array}{c}- \\
\text { (na) }\end{array}$ \\
\hline SES $\rightarrow$ Disruption & $\begin{array}{c}.30 \\
\text { (na) }\end{array}$ & $\begin{array}{c}.30 \\
\text { (na) }\end{array}$ & $\begin{array}{c}.30 \\
\text { (na) }\end{array}$ \\
\hline $\mathrm{SES} \rightarrow$ Control over aftershocks & $\begin{array}{c}-.49 \\
(-.49)\end{array}$ & $\begin{array}{c}-.46 \\
(-.46)\end{array}$ & $\begin{array}{c}-.48 \\
(-.48)\end{array}$ \\
\hline SES $\rightarrow$ Aftershock anxiety & $\begin{array}{c}- \\
(-.26) \\
\end{array}$ & $\begin{array}{c}- \\
(-.24) \\
\end{array}$ & $\begin{array}{c}- \\
(-.25)\end{array}$ \\
\hline SES $\rightarrow$ Anxiety/stress/depression & $\begin{array}{c}- \\
(-.23) \\
\end{array}$ & $\begin{array}{c}- \\
(-.11)\end{array}$ & $\begin{array}{c}-.14 \\
(-.21)\end{array}$ \\
\hline SES $\rightarrow$ General Functioning & $\begin{array}{c}- \\
(-)\end{array}$ & $\begin{array}{c}- \\
(-)\end{array}$ & $\begin{array}{c}- \\
(-)\end{array}$ \\
\hline SES $\rightarrow$ Relationship Functioning & $\begin{array}{l}- \\
(-)\end{array}$ & $(-)$ & $\begin{array}{l}- \\
(-)\end{array}$ \\
\hline Loss $\rightarrow$ Disruption & $\begin{array}{c}.14 \\
\text { (na) }\end{array}$ & $\begin{array}{l}.13 \\
\text { (na) }\end{array}$ & $\begin{array}{c}.13 \\
\text { (na) }\end{array}$ \\
\hline Loss $\rightarrow$ Control over aftershocks & $\begin{array}{c}- \\
\text { (na) }\end{array}$ & $\begin{array}{c}- \\
\text { (na) }\end{array}$ & $\begin{array}{c}- \\
\text { (na) }\end{array}$ \\
\hline
\end{tabular}




\begin{tabular}{|c|c|c|c|}
\hline Loss $\rightarrow$ Aftershock anxiety & $\begin{array}{c}- \\
(-)\end{array}$ & $\begin{array}{l}- \\
(-)\end{array}$ & $\begin{array}{l}- \\
(-)\end{array}$ \\
\hline Loss $\rightarrow$ Anxiety/stress/depression & $\begin{array}{c}- \\
(-)\end{array}$ & $\begin{array}{l}- \\
(-)\end{array}$ & $\begin{array}{c}- \\
(-)\end{array}$ \\
\hline Loss $\rightarrow$ Relationship Functioning & $\begin{array}{c}.13 \\
(.15)\end{array}$ & $\begin{array}{c}.11 \\
(.14)\end{array}$ & $\begin{array}{l}- \\
(-)\end{array}$ \\
\hline Loss $\rightarrow$ General Functioning & $\begin{array}{l}.15 \\
(.18)\end{array}$ & $\begin{array}{l}.15 \\
(.19)\end{array}$ & $\begin{array}{l}.11 \\
(.17)\end{array}$ \\
\hline Disruption $\rightarrow$ Control over aftershocks & $\begin{array}{c}- \\
\text { (na) }\end{array}$ & $\begin{array}{c}- \\
(\mathrm{na})\end{array}$ & $\begin{array}{c}- \\
(\mathrm{na})\end{array}$ \\
\hline Disruption $\rightarrow$ Aftershock anxiety & $\begin{array}{c}.13 \\
(.13) \\
\end{array}$ & $\begin{array}{c}.14 \\
(.14) \\
\end{array}$ & $\begin{array}{c}.13 \\
(.14) \\
\end{array}$ \\
\hline Disruption $\rightarrow$ Anxiety/stress/depression & $(-)$ & $\begin{array}{l}.19 \\
(.28)\end{array}$ & $\begin{array}{l}.18 \\
(.25)\end{array}$ \\
\hline Disruption $\rightarrow$ Relationship Functioning & $\begin{array}{l}.13 \\
(.16)\end{array}$ & $\begin{array}{l}.15 \\
(.25)\end{array}$ & $\begin{array}{l}.16 \\
(.25)\end{array}$ \\
\hline Disruption $\rightarrow$ General Functioning & $\begin{array}{c}.20 \\
(.23) \\
\end{array}$ & $\begin{array}{c}.26 \\
(.33) \\
\end{array}$ & $\begin{array}{c}.18 \\
(.26) \\
\end{array}$ \\
\hline Control over aftershocks $\rightarrow$ Aftershock anxiety & $\begin{array}{c}.61 \\
\text { (na) }\end{array}$ & $\begin{array}{c}.61 \\
\text { (na) }\end{array}$ & $\begin{array}{l}.60 \\
\text { (na) } \\
\end{array}$ \\
\hline Control over aftershocks $\rightarrow$ Anxiety/stress/depression & $\begin{array}{c}.14 \\
(.52)\end{array}$ & $\begin{array}{c}- \\
(.42)\end{array}$ & $\begin{array}{c}- \\
(.31)\end{array}$ \\
\hline Control over aftershocks $\rightarrow$ Relationship Functioning & $\begin{array}{l}- \\
(-)\end{array}$ & $\begin{array}{c}- \\
(.11)\end{array}$ & $\begin{array}{c}- \\
(.12) \\
\end{array}$ \\
\hline Control over aftershocks $\rightarrow$ General Functioning & $\begin{array}{c}- \\
(.16)\end{array}$ & $\begin{array}{c}- \\
(.15)\end{array}$ & $\begin{array}{c}- \\
(.10) \\
\end{array}$ \\
\hline Aftershock anxiety $\rightarrow$ Anxiety/stress/depression & $\begin{array}{l}.63 \\
\text { (na) }\end{array}$ & $\begin{array}{l}.69 \\
\text { (na) }\end{array}$ & $\begin{array}{l}.52 \\
\text { (na) }\end{array}$ \\
\hline Aftershock anxiety $\rightarrow$ Relationship Functioning & $\begin{array}{c}- \\
(.26)\end{array}$ & $(.24)$ & $\begin{array}{c}- \\
(.19)\end{array}$ \\
\hline Aftershock anxiety $\rightarrow$ General Functioning & $(.20)$ & $\begin{array}{c}- \\
(.18)\end{array}$ & $\begin{array}{c}- \\
(.16)\end{array}$ \\
\hline Anxiety/stress/depression $\rightarrow$ Relationship Functioning & $\begin{array}{c}.42 \\
\text { (na) }\end{array}$ & $\begin{array}{r}.35 \\
\text { (na) } \\
\end{array}$ & $\begin{array}{c}.37 \\
\text { (na) } \\
\end{array}$ \\
\hline Anxiety/stress/depression $\rightarrow$ General Functioning & $\begin{array}{c}.32 \\
\text { (na) } \\
\end{array}$ & $\begin{array}{r}.26 \\
\text { (na) } \\
\end{array}$ & $\begin{array}{c}.32 \\
\text { (na) } \\
\end{array}$ \\
\hline
\end{tabular}

Notes: - = no substantial or significant relationships; na = not applicable (i.e., no indirect pathway, just direct) 
Figure 2: Generalized accepted model (excluding neighborhood damage as it had no direct relationship to aftershock variables)

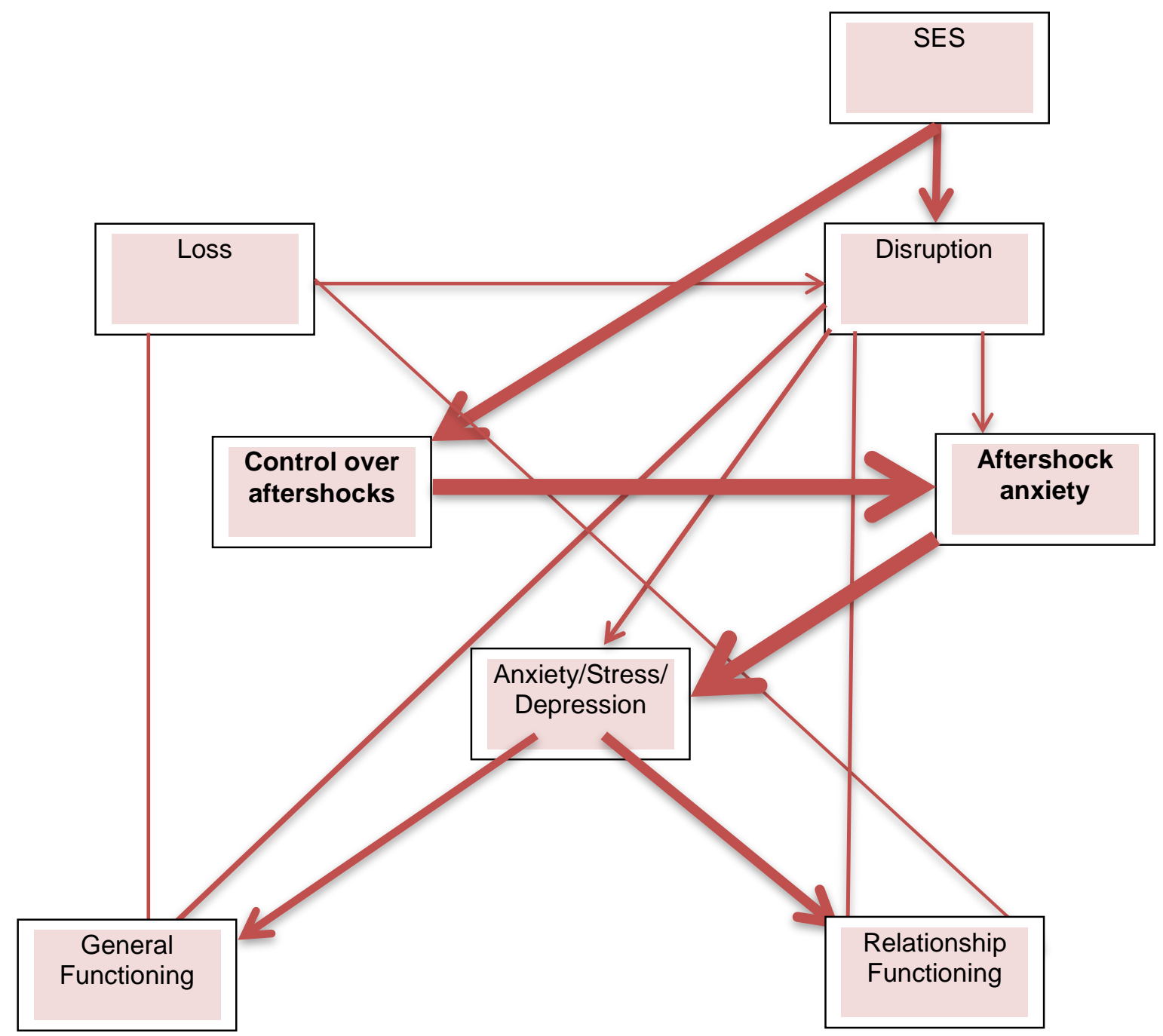

